\title{
Clinical Outcome of Herbal Medicine-related Problems for Respiratory Viral Infections
}

\author{
Yousef Ahmed Alomi*, (D) BSC. \\ Pharm, MSc. Clin Pharm, BCPS, BCNSP, DiBA, \\ CDE, Critical Care Clinical Pharmacists, TPN \\ Clinical Pharmacist, Freelancer Business \\ Planner, Content Editor, and Data Analyst, \\ Riyadh, SAUDI ARABIA.
}

Ghadeer Alhazmi, Department of Medicine and Surgery, College of Medicine, Umm Al-Qura University, Makkah,

SAUDI ARABIA.

Murouj Almaghrabi, Department

of Medicine and Surgery, College of

Medicine, Umm Al-Qura University, Makkah, SAUDI ARABIA.

Ghaida Alzahrani, Department of

Medicine and Surgery, College of Medicine, Umm Al-Qura University, Makkah,

SAUDI ARABIA.

Mohammad Almatrafi, Department

of Medicine and Surgery, College of

Medicine, Umm Al-Qura University,

Makkah, SAUDI ARABIA.

\section{Correspondence:}

Dr. Yousef Ahmed Alomi, Bsc. Pharm, Msc. Clin pharm, BCPS, BCNSP, DiBA, CDE Critical Care Clinical Pharmacists, TPN Clinical

Pharmacist, Freelancer Business Planner, Content Editor and Data Analyst, P.O.BOX 100, Riyadh 11392, Riyadh, SAUDI ARABIA. Phone no: +966 504417712

E-mail:yalomi@gmail.com
Received: 07-01-2021;

Accepted: 29-03-2021;

Copyright: () the author(s), publisher and licensee International Journal of Pharmacology and Clinical Sciences. This is an open-access article distributed under the terms of the Creative Commons

Attribution Non-Commercial License, which permits unrestricted non-commercial use, distribution, and reproduction in any medium, provided the original work is properly cited.

This is an open access article distributed under the terms of the Creative Commons AttributionNonCommercial-ShareAlike 4.0 License

\section{Access this article online}

\begin{tabular}{|c|c|}
\hline & www.ijpcs.net \\
\hline & DOI: \\
\hline
\end{tabular}

\begin{abstract}
Background: The use of herbal medicine to treat dissimilar respiratory conditions has been assumed for many decades. This survey analysis explores the clinical outcomes of herbal medicine-related problems for respiratory viral infections in Saudi Arabia. Design and Setting: A self-administered, structured questionnaire was sent to the public online, counting questions on the responders' demographics and questions gaging different clinical outcomes of herbal medicine-related problems when treating respiratory viral infections in Saudi Arabia. Data analysis was performed through SPSS program version 26. Results: 486 participants responded to this questionnaire. $89.92 \%$ of the responders were from the west area in Saudi Arabia, 56.49\% were in the age group between 18 and 30 years old. $18.32 \%$ were healthcare practitioners, while $53.85 \%$ of these practitioners were physicians. $18.74 \%$ of the responders applied herbal medications three times daily for respiratory viral infections. Only $4.31 \%$ of the responders established having side effects during the past year from herbal medications, while $3.58 \%$ visited a pharmacy for these side effects. Their healthcare professionals asked $20.04 \%$ about the use of herbal medications. Factors increasing the occurrence of adverse events were: that residents of the western region ( $p$ value $=0.002$ ), age group between 18 and 30 ( $p$-value $=0.046)$, females $(p$-value $<0.001)$, low monthly income $(p$-value $=0.013)$ and non-healthcare professionals $(p$-value $=0.001)$. Conclusion: Although the occurrence of herbal medication-related problems is not common in Saudi Arabia, it can need medical assistance. Awareness of the public of the herbal medications adverse events is decisive.

Key words: Clinical, Outcome, Herbal Medicine, Problems, Viral Infections Saudi Arabia.
\end{abstract}

\section{INTRODUCTION}

Patient safety is flattering an essential part of medical practice. ${ }^{[1]}$ Guaranteeing that medications are safe and operative and is vital for the current approval of any new medications. [2] This is also used for herbal medicines that are totally or partially of herbal origin. [3] Consequently, pharmaceutical companies are now mandatory to mention the incidence of every adverse event. ${ }^{[4]}$ Although there is an inherited belief that herbal medications are safe, many herbal medicines have been conveyed for adverse events and withdrawn from the market during the past few years. ${ }^{[5]}$

The major drug-related problems are usually related to wrong doses, wrong route, wrong method of administration, incorrect indication, allergy, or occurrence of adverse effects. [6] However, recently a new pharmaceutical discipline has been familiarised, which is pharmacovigilance. $^{[7]}$ This new field permits better tracking for drug-related problems, not only of chemical origin but also of herbal origin, thus allowing better management for these problems. ${ }^{[8]}$

Despite all these strategies for classifying and solving drug-related problems, public and even healthcare professionals' awareness about reporting adverse events for medications, especially herbal ones, is mediocre ${ }^{[9]}$ Accordingly, the clinical outcomes of these problems remain unidentified and undervalued. ${ }^{[10]}$ Hence, evaluating clinical outcomes of common herbal medication-related problems should come first through patients themselves. ${ }^{[11]}$

The problem of herbal medication-related problems is even more convoluted. It is attributed to the more common use of herbal medications and their availability as overthe-counter medications, expressly in the gulf area. ${ }^{[12]}$ Consequently, the reporting and identification of these problems is nearly absent and entails exploration. Accordingly, the existing study inspects the clinical outcomes of herbal medicine-related issues to treat viral respiratory infections in Saudi Arabia.

\section{MATERIALS AND METHODS}

\section{Study Design}

This quantitative cross-sectional survey study was carried out in Saudi Arabia through a self-administered electronic questionnaire for two months. All Saudi Arabia citizens were comprised. The survey was interview-based at shopping malls, parks, hospitals and mosques online. 


\section{Data Collection}

An online interview-based questionnaire was dispersed to members of the public in different regions in Saudi Arabia. The first part of the survey encompassed the demographics of the included participants. While the second part comprised information about the duration of using herbal medications over the last 12 months and any side effects due to herbal medication use over the previous 12 months. Besides, suppose a physician or pharmacist asks you about your herbal medicines before starting the treatment and any side effects or problems using herbal medications. In that case, that leads to any visits to the pharmacy or clinic, hospital admission general wards, or critical care services. A 5-point Likert response scale system was applied. The survey had been disseminated to a convenient sample of public responders. It was through social media of WhatsApp and telegram, and personal contact. The prompt message is sent every 1-2 weeks. The completed survey and Saudi public will be encompassed in the final analysis.

\section{Statistical Analyses}

According to the earlier literature with unlimited population size, the sample was calculated, the population percentage of $50 \%$, the confidence level $95 \%$, with a $\mathrm{z}$ score of 1.96 and margin of error 5\%, and drop-out rate $10 \%$. As a result, the sample size calculated as a minimum sample of 418 with the power of study of $80 \% \cdot{ }^{[13-15]}$ The response rate mandatory of calculated sample size at least $60-70 \%$ and above. ${ }^{[15,16]}$ The survey was authenticated through the revision of expert reviewers and pilot testing. Moreover, the reliability tests McDonald's $\omega$, Cronbach's a, Guttmann's 2, and Guttmann's. The data analysis was finalized through the survey monkey system. In addition, the statistical package of social sciences (SPSS), Jeffery's Amazing Statistics Program (JASP), and Microsoft excel sheet version 16 with description and frequency analysis, good fitness analysis, correlation analysis, inferential analysis between independent variables responders. The STROBE (Strengthening the reporting of observational studies in epidemiology statement: guidelines for reporting observational studies) directed the existing study's reporting. ${ }^{[17,18]}$

\section{RESULTS}

Four hundred and eighty-six responders contributed in this online questionnaire. Only participants who finished all the sections in the questionnaire were comprised. Therefore, the reliability test of Mac, Cronbach, Guttmann 2, and Guttmann 6 cannot be used because all data and variables were nominal data. Socio- demographics of responders and analysis of the questionnaire are shown below.

\section{General Characters of Responders}

Out of 486 participants, $89.92 \%$ of the responders were from the west area with statistically significant differences with other regions $(p<0.001)$, and $94.62 \%$ had a Saudi nationality. Also, $80.45 \%$ were females with statistically momentous differences from males $(p<0.001)$, where $59.17 \%$ were single. As for the age of the responders, it was considered into seven sub-categories. The most prevalent age group was between 18 and 30 years old, with $56.49 \%$ of the responses with statistically significant differences between age groups $(p<0.001)$. All socio-demographic data is exposed in detail in Table 1.

\section{Social and Professional Information of the Responders}

Regarding the responders' education level, $66.1 \%$ had a bachelor's degree, while $46.27 \%$ were still students, and only $23.44 \%$ were employees, with statistically significant differences among them $(p<0.001)$. Monthly income was also assessed; it has been shown that $53.69 \%$ had an income $<3000$ SR with statistically significant differences with other responder's incomes $(p<0.001)$. Participants

\begin{tabular}{|c|c|c|c|}
\hline Nationality & Response Count & Response Percent & $p$-value \\
\hline Central area & 11 & $2.26 \%$ & \multirow[t]{5}{*}{$<0.001$} \\
\hline North area & 6 & $1.23 \%$ & \\
\hline South area & 20 & $4.12 \%$ & \\
\hline East area & 12 & $2.47 \%$ & \\
\hline West area & 437 & $89.92 \%$ & \\
\hline Answered question & 486 & & \\
\hline Skipped question & 0 & & \\
\hline Nationality & Response Count & Response Percent & \\
\hline Saudi & 457 & $94.62 \%$ & \multirow[t]{2}{*}{$<0.001$} \\
\hline Non-Saudi & 26 & $5.38 \%$ & \\
\hline Answered question & 483 & & \\
\hline Skipped question & 3 & & \\
\hline Gender & Response Count & Response Percent & \\
\hline Female & 391 & $80.45 \%$ & \multirow[t]{2}{*}{$<0.001$} \\
\hline Male & 95 & $19.55 \%$ & \\
\hline Answered question & 486 & & \\
\hline Skipped question & 0 & & \\
\hline Material Status & Response Count & Response Percent & \\
\hline Single & 284 & $59.17 \%$ & \multirow[t]{3}{*}{$<0.001$} \\
\hline Married & 187 & $38.96 \%$ & \\
\hline Divorced & 9 & $1.88 \%$ & \\
\hline Answered question & 480 & & \\
\hline Skipped question & 6 & & \\
\hline Age & Response Count & Response Percent & \\
\hline$<18$ & 32 & $6.60 \%$ & \multirow[t]{7}{*}{$<0.001$} \\
\hline $18-30$ & 274 & $56.49 \%$ & \\
\hline $31-40$ & 81 & $16.70 \%$ & \\
\hline $41-50$ & 58 & $11.96 \%$ & \\
\hline $51-60$ & 22 & $4.54 \%$ & \\
\hline $61-70$ & 15 & $3.09 \%$ & \\
\hline$>70$ & 3 & $0.62 \%$ & \\
\hline Answered question & 485 & & \\
\hline Skipped question & 1 & & \\
\hline
\end{tabular}


were also requested if they were working in the medical field. Only $18.32 \%$ were healthcare practitioners, while $53.85 \%$ of these practitioners were physicians with statistically substantial differences with other specialties $(p<0.001)$, as shown in Table 2.

\section{Use of Herbal Medications over the Last 12 Months}

Responders were requested about their use of herbal medicines during the preceding 12 months for respiratory viral infections. $18.74 \%$ of the responders used them three times daily, while $41.89 \%$ have never applied herbal medications for this purpose, and $2.53 \%$ of the responders used them for one month. Additionally, $36.82 \%$ used herbal medicines solely, while $29.22 \%$ used them with other regularly approved medications with statistically significant differences between them $(p<0.001)$.

Participants were also enquired about the incidence of side effects because of herbal medications. Only $4.31 \%$ of the responders established having side effects during the past year from herbal medicines, while only $3.58 \%$ visited a pharmacy for these side effects. In addition, just below half of the responders (42.57\%) educated their healthcare professionals about the use of herbal medications. In comparison, only $20.04 \%$ of the responders were asked by their healthcare professionals about herbal medicines, as shown in Table 3.

Furthermore, the responders were inquired about their use of herbal medications for dental management with other medicines. $55.18 \%$ of the responders did not apply herbal medication with any other medical conditions. In comparison, $18.77 \%$ of the patients used herbal medications concurrently with asthma and respiratory disease medications, as shown in Table 4.

\section{Independent Variable Analysis Age}

There is no statistically noteworthy difference between males and females in different regions, ages, material status, nationality, healthcare provider or public, and healthcare professionals spheres $(p>0.05)$. In contrast, the male $12(63 \%)$ is higher than female $3(0.74 \%)$ in age 61 years old and above with statistically significant alteration $(p<0.05)$. The male has higher academic qualifications than females master degree $12(12.77 \%)$ vs. $17(4.24 \%)$ or diploma 9 (9.57\% vs. 14 (3.49\%), while females more had of bachelor's degree 271 (67.58\%) vs. $53(56.38 \%)$ with statistically significant difference $(p<0.05)$. The males more engaged than female $32(34.04 \%)$ vs. $84(20.9 \%)$, and

\begin{tabular}{|c|c|c|c|}
\hline Responder Qualifications & Response Count & Response Percent & $p$-value \\
\hline Doctorate & 10 & $2.08 \%$ & \multirow[t]{8}{*}{$<0.001$} \\
\hline Master's degree & 28 & $5.82 \%$ & \\
\hline Bachelor's degree & 318 & $66.11 \%$ & \\
\hline Diploma & 21 & $4.37 \%$ & \\
\hline High school & 99 & $20.58 \%$ & \\
\hline Intermediate School & 3 & $0.62 \%$ & \\
\hline Primary School & 1 & $0.21 \%$ & \\
\hline Not educated & 1 & $0.21 \%$ & \\
\hline Answered question & 481 & & \\
\hline Skipped question & 7 & & \\
\hline Occupational status & Response Count & Response Percent & \\
\hline Employee & 113 & $23.44 \%$ & \multirow[t]{4}{*}{$<0.001$} \\
\hline Non-employee & 109 & $22.61 \%$ & \\
\hline Retried & 37 & $7.68 \%$ & \\
\hline Student & 223 & $46.27 \%$ & \\
\hline Answered question & 482 & & \\
\hline Skipped question & 4 & & \\
\hline Monthly income & Response Count & Response Percent & \\
\hline$<3000 \mathrm{SR}$ & 233 & $53.69 \%$ & \multirow[t]{5}{*}{$<0.001$} \\
\hline $3001-6000$ SR & 37 & $8.53 \%$ & \\
\hline 6001-9000 SR & 38 & $8.76 \%$ & \\
\hline 9001-12000 SR & 44 & $10.14 \%$ & \\
\hline$>12000$ SR & 82 & $18.89 \%$ & \\
\hline Answered question & 434 & & \\
\hline Skipped question & 52 & & \\
\hline $\begin{array}{l}\text { Are you a health care } \\
\text { practitioner (Medical Doctor- } \\
\text { Dentist- Pharmacist- Nurse- } \\
\text { Others? }\end{array}$ & Response Count & Response Percent & \\
\hline Yes & 87 & $18.32 \%$ & \multirow[t]{2}{*}{$<0.001$} \\
\hline No & 388 & $81.68 \%$ & \\
\hline Answered question & 475 & & \\
\hline Skipped question & 11 & & \\
\hline $\begin{array}{l}\text { If you are a health care } \\
\text { practitioner, you are a }\end{array}$ & Response Count & Response Percent & \\
\hline Physician & 49 & $53.85 \%$ & \multirow[t]{4}{*}{$<0.001$} \\
\hline Dentist & 6 & $6.59 \%$ & \\
\hline Pharmacist & 8 & $8.79 \%$ & \\
\hline Nurse & 28 & $30.77 \%$ & \\
\hline Other (please specify) & 66 & & \\
\hline Answered question & 91 & & \\
\hline Skipped question & 395 & & \\
\hline
\end{tabular}

more retried 19 (2021\%) vs. 18 (4.48\%), while more females of non-employed 111 (27.61\%) vs. $8(8.51 \%)$ with statistically significant difference $(p<0.05)$. The males had a higher monthly income ( $>12,000$ SR) than females, 27
(30\%) vs. $56(15.77 \%)$. In contrast, the female had inferior monthly income than males, 200 $(56.34 \%)$ vs. $37(41.11 \%)$, with a statistically substantial difference $(p<0.05)$. 


\section{Healthcare Provider's vs. Public}

There is no statistically weighty difference between responders healthcare providers and public residents in living regions, gender, nationality and monthly income $(p>0.05)$. However, the age of healthcare providers is advanced than the public with (18-30 years) $72(80.9 \%)$ vs. 196 (49.25\%). In contrast, the people higher than professionals in ages (41-50 years) with percent $58(14.57 \%)$ vs. $1(1.12 \%)$, and age (51-60) with percent $22(5.53 \%)$ vs. $0(0 \%)$ with statistically noteworthy difference $(p<0.05)$. Most healthcare professionals were single $70(80.46 \%)$ vs. public 208 (52.66\%), while the majority of public responders were married $180(45.57 \%)$ vs. healthcare professionals 16 (18.39\%) with statistically significant difference $(p<0.05)$. The healthcare providers had more bachelor's degree $70(79.55 \%)$ than public 248 (62.78\%), while the public had a more high school degree $90(22.78 \%)$ than healthcare providers $10 \quad(11.36 \%)$ with statistically significant difference $(p<0.05)$. The public responders had more non-employment 106 (26.77\%) and retired 37 (9.34\%) than healthcare providers $12(13.64 \%)$ and $0(0 \%)$ respectively. In contrast, the healthcare providers had more student qualifications 56 (63.64\%) than public responders $160(40.4 \%)$, with a statistically momentous difference $(p<0.05)$.

\section{Nationality}

There is no statistically important difference between Saudi and non-Saudi in the different regions came from, ages group, gender, material status, educational levels, occupational status, monthly income, healthcare provider or public, and healthcare professionals subjects $(p>0.05)$

\section{Independent Variable Correlation}

There is a positive suggestion between age and material status and monthly income with spearman outcomes (0.738) and (0.566) respectively, while the Kendal taw was (0.678), (0.499) with statistically significant $(p<0.001)$. In contrast, there was a negative overtone between age and occupational status with spearman results $(-0.582)$ and Kendal taw $(-0.83)$ with statistically significant $(p<0.001)$. There was a positive association between material status and monthly income of spearman results was 0.518 and Kendal taw (0.476) with statistically significant $(p<0.001)$. While there was a negative correlation between material status and occupational level, spearman's results were -0.627 and Kendal taw (-0.580) with statistically noteworthy $(p<0.001)$. There is a negative correlation between occupational levels and monthly income with spearman results $(-0.578)$ and Kendal taw (-0.501) with statistically momentous $(p<0.001)$.
Table 3: Herbal medicine-related problems.

How many days have you used herbal medications over the last 12 months for respiratory viral management?

one day

three-time

one week

Two weeks

one month

more than one month

never

Answered question

Skipped question

How did use herbal medications for respiratory viral

management

I used alone

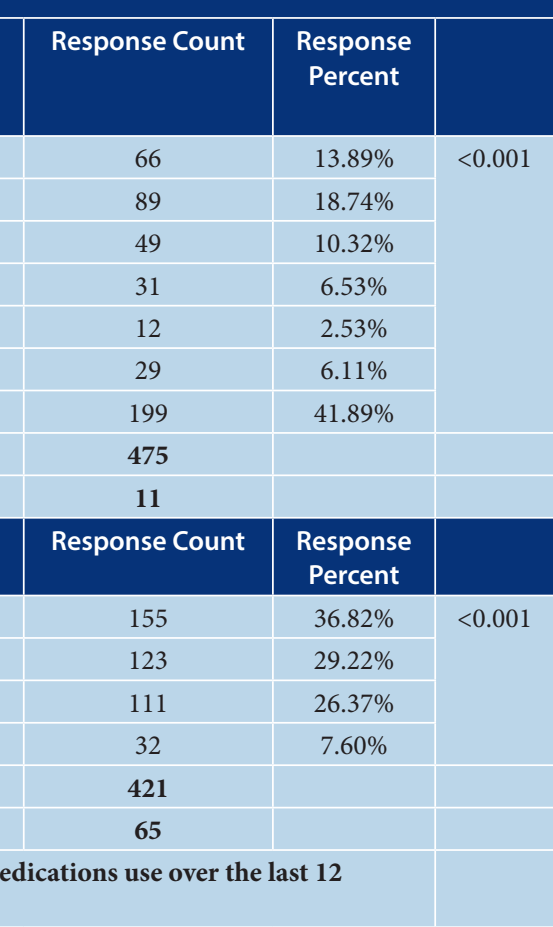

I used it with regular medications

I used medicine from a physician

Other (please specify)

Answered question

Skipped question

\begin{tabular}{|l|c|c|}
\hline $\begin{array}{l}\text { Have you suffered from any side effects due to herbal } \\
\text { medications use over the last } \mathbf{1 2} \text { months? }\end{array}$ & \multicolumn{2}{|c|}{ Responses } \\
\hline Yes & 19 & $4.31 \%$ \\
\hline No & 330 & $74.83 \%$ \\
\hline uncertain & 92 & $20.86 \%$ \\
\hline Answered & $\mathbf{4 4 1}$ & \\
\hline
\end{tabular}

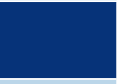

$<0.001$

Skipped

Have you informed your physician about using herbal medications??

\begin{tabular}{|l|c|c|}
\hline $\begin{array}{l}\text { Have you informed your physician about using herbal } \\
\text { medications?? }\end{array}$ & \multicolumn{2}{|c|}{ Responses } \\
\hline Yes & 189 & $42.57 \%$ \\
\hline No & 193 & $43.47 \%$ \\
\hline uncertain & 62 & $13.96 \%$ \\
\hline Answered & $\mathbf{4 4 4}$ & \\
\hline Skipped & $\mathbf{4 2}$ & \\
\hline
\end{tabular}

Have you ever the physician or pharmacist asked you about your herbal medication use before starting the treatment?

\begin{tabular}{l|c|c|}
\hline $\begin{array}{l}\text { Have you ever the physician or pharmacist asked you } \\
\text { about your herbal medication use before starting the } \\
\text { treatment? }\end{array}$ & \multicolumn{2}{|c|}{ Responses } \\
\hline Yes & 90 & $20.04 \%$ \\
\hline No & 262 & $58.35 \%$ \\
\hline uncertain & 97 & $21.60 \%$ \\
\hline Answered & 449 & \\
\hline Skipped & 37 & \\
\hline
\end{tabular}

Have you ever had any side effects or problems from using herbal medications that lead to any of the following..?

\begin{tabular}{|l|c|c|}
\hline $\begin{array}{l}\text { Have you ever had any side effects or problems from } \\
\text { using herbal medications that lead to any of the } \\
\text { following..? }\end{array}$ & \multicolumn{2}{|c|}{ Responses } \\
\hline visit the pharmacy & 15 & $3.58 \%$ \\
\hline visit the physician office & 2 & $0.48 \%$ \\
\hline visit the emergency department & 8 & $1.91 \%$ \\
\hline hospital admission & 6 & $1.43 \%$ \\
\hline
\end{tabular}




\begin{tabular}{|l|c|c|}
\hline admission to critical care & 2 & $0.48 \%$ \\
\hline Nothing happened at all & 375 & $89.50 \%$ \\
\hline Other (please specify) & 21 & $5.01 \%$ \\
\hline Answered & $\mathbf{4 1 9}$ & $3.58 \%$ \\
\hline Skipped & $\mathbf{6 7}$ & $0.48 \%$ \\
\hline
\end{tabular}

Table 4: The herbal medications usage for dental management with other medications.

Do you use herbal medications for dental management with any of the following medical conditions?

\section{Answer Choices}

epilepsy and nerve diseases medications

Asthma and respiratory diseases medications

cardiac diseases medications

blood diseases medications

Anti-diabetes medications

high/ low blood pressure medications

digestive tract disease medications

Antineoplastic medications

I don't use herbal medications in the presence of any medical conditions

Other (please specify)

Answered

Skipped

\section{DISCUSSION}

Drug-related problems are one of the chief worries of using medications. It occupied a very high economic burden on the healthcare system in Saudi Arabia and else wide world. During of use for the treatment of viral infection with importance on COVID-19 is without a problem. However, each medication had a tricky that included adverse events. There is a general insight among the public's known members, counting healthcare professionals, that the use of herbal medications is generally safe. ${ }^{[19]}$ However, it should be illustrious that some herbal medicines can have serious adverse events that may reach death (such as with digitalis) if not used properly or if they interacted with other medications. ${ }^{[20]}$ Accordingly, guessing the Figures of drugrelated problems arising from the use of herbal medicines are decisive.

The present search intended to assess the clinical outcomes of herbal medicine-related problems for respiratory viral infections among the Saudi population. The study reconnoitred the majority of responders from the west area, young age with student occupational status, and single with low monthly income because some authors worked as data collectors. They were students at the college of medicine at Um Alora University, located in the west region, and collected sufficiently from their society. The demographic information of the sample study has contained of two parts included public and healthcare professionals. The majority type was public residents, with one-fifth of healthcare providers. Most of the public is older, married, non-employments with low salaries and low academic qualifications.

In contrast, the healthcare providers were young, single, with employments, high academic qualifications. The demographic information was imitated in the entire society. There are no statistically significant differences between public and non-public responders in gender or nationality, monthly income. The responder's demographic data was decent that replicated the actual characters of Saudi populations. Those properly echoed the actual behaviour of usage of herbal medications during viral infection, highlighting coronavirus. There was a medium positive correlation between age, marital status, and high financial income. On the other hand, a negative correlation between occupational status, younger age, and student's positions, while old age linked with higher academic qualifications, counting mater science degree, had a negative connotation. Moreover, there was a negative correlation between income and occupational status, reproducing reliable social practice.

In the contemporary study to examine drugrelated might ensued during viral illness management. The study displayed that one- fifth of them used herbal medicine to treat viral infection daily with high frequency, while low perception was applied for a long time. During those periods, the patients will agonise from adverse effects from high dose or long term used. Herbal medication-related problems have been deliberated in different settings in the medical literature. For example, Lüde et al. ${ }^{[21]}$ inspected the adverse events testified from a poisons center from herbal supplements and other herbal agents used as food. Lüde et al. ${ }^{[21]}$ comprised 75 patients admitted to ten European and Brazilian poison centres. 76\% of the patients had adverse events from using herbal supplements with liquorice and mint on the top 10 list of herbal agents. Although most of the cases conveyed by Lüde et al. ${ }^{[21]}$ were mild, five patients were in severe condition.

In compliance with the findings of Lüde et al. ${ }^{[21]}$ the current study exposed that the occurrence of adverse drug problems from herbal agents for respiratory viral infections is generally stumpy (not more than 5\%), with mild concerns. However, it should be distinguished that some serious adverse events or mortalities might be under-reported. Also, only one-fifth of the encompassed responders were asked by their clinicians about herbal agents' use, underlining a negative attitude from healthcare professionals.

The one-third percentage applied herbal medications alone or with regular medicines. The drug-related problems might happen during viral infection treatment; it was an herbal drug interaction problem. Most of our responders used herbal medicines for asthma or respiratory infection or GIT problem, or anti-diabetic medications that the herbal might interrelate with their regular medication. A systematic review by Posadzki et al. ${ }^{[22]}$ appraised the drug interactions by herbal agents. Posadzki et al. ${ }^{[22]}$ disclosed that serious interactions or consequences do not attend most herbal agents. However, the strength of the comprised studies was low. Although these findings obey with the present study, further inquiries are still mandatory.

Another systematic review by Lzzo et al. ${ }^{[23]}$ scrutinised the adverse events and drug-related problems ascending from herbal medications. Lzzo et al. ${ }^{[23]}$ involved different herbal agents to treat the common cold, premenstrual complaints, hypertension, and nausea during pregnancy, menopause, and hyperglycaemia. Lzzo et al. ${ }^{[23]}$ established that despite a better tolerance for herbal medications compared to medications of chemical origin, the frequency of serious adverse events or drug interactions should be measured. These recommendations by Lzzo et al. ${ }^{[23]}$ upkeep the present examination. Although less than 
$5 \%$ of the comprised participants had adverse events from herbal medications, it is unknown if any encompassed subjects were from a sole population with a higher risk of adverse events, such as cancer or pregnant patients.

The responders specified that some herbalrelated problems ensued to them and progress of numerous percentages of emergency visits or hospital admissions or critical care admission according to the severity of ADR. Those drug-related problems that followed might be related to herbal medications history were not recognized because almost half of the responders did not notify the treating physicians about their usage of herbal medications. Sometimes, the healthcare provider enquired the patients about their history of herbal medication usage. All drugs applied for viral infection with importance on COVID-19 had drug-related problems, counting herbal medications. All drug-related problems of herbal medicines need to close monitoring and treat consequently. A medication reconciliation system should be executed to prevent any herbal medication-related problems during viral illness management in future.

Additionally, the existing study had some confines; the participants' responses depend largely on the responders' subjective opinion towards the adverse events that happened to them after using herbal medications, which could disturb the reliability of the outcomes. Nevertheless, it is measured the first study in Saudi Arabia to assess herbal medications' clinical outcomes related to respiratory viral infections.

\section{CONCLUSION}

Herbal drug-related problems are usually significant in Saudi Arabia, with frequently lead pharmacy visits or emergency and hospital admission. However, the public's awareness and healthcare professionals towards the adverse effects of herbal medications should be upgraded. It can be accomplished through national campaigns by pharmaceutical companies and healthcare organizations. Additionally, further research is obligatory to discover the incidence of adverse events from herbal medications for other indications, which could be more serious than those offered in the contemporary study.

\section{ACKNOWLEDGEMENT}

None.

\section{CONFLICT OF INTEREST}

The authors declare that there is no conflict of interest.

\section{Funding}

None

\section{Consent for Publications}

Informed consent was obtained from all the participants

\section{Ethical Approval}

This research is exempted from research and ethical committee or an institutional review board (IRB) approval.

https://www.hhs.gov/ohrp/regulations-andpolicy/decision-charts-2018/index.html

\section{ABBREVIATIONS}

MOH: Ministry of Health; KSA: Kingdom of Saudi Arabia; Covid-19: Coronavirus; SPSS: Statistical Package of Social Sciences; JASP: Jeffery's Amazing Statistics Program; Strobe: Strengthening the reporting of observational studies in epidemiology statement: guidelines for reporting observational studies.

\section{ORCID ID}

Yousef Ahmed Alomi (iD https://orcid.org/ 0000-0003-1381-628X

Murouj Adnan Almaghrabi (iD https://orcid. org/0000-0001-7357-9269

\section{REFERENCES}

1. Di Lorenzo C, Ceschi A, Kupferschmidt H, Lüde S, De Souza Nascimento E, Dos Santos A, et al. Adverse effects of plant food supplements and botanical preparations: A systematic review with critical evaluation of causality. Br J Clin Pharmacol. 2015;79(4):578-92. doi: 10.1111/bcp.12519, PMID 25251944.

2. Di Minno A, Frigerio B, Spadarella G, Ravani A, Sansaro D, Amato $M$, et al. Old and new oral anticoagulants: food, herbal medicines and drug interactions. Blood Rev. 2017;31(4):193-203. doi: 10.1016/j.blre.2017.02.001, PMID 28196633.

3. Onakpoya IJ, Heneghan CJ, Aronson JK. Postmarketing withdrawal of 462 medicinal products because of adverse drug reactions: A systematic review of the world literature. BMC Med. 2016;14(1):10. doi: 10.1186/s12916-016-0553-2, PMID 26843061.

4. Karimi A, Majlesi M, Rafieian-Kopaei M Herbal versus synthetic drugs; beliefs and facts J Nephropharmacol. 2015;4(1):27-30. PMID 28197471.

5. Hong M, Li S, Tan HY, Cheung F, Wang N, Huang J, Feng $Y$. A network-based pharmacology study of the herb-induced liver injury potential of traditional hepatoprotective Chinese herbal medicines. Molecules. 2017;22(4). doi: 10.3390/ molecules22040632, PMID 28420096.

6. Sarker A, Gonzalez G. Portable automatic text classification for adverse drug reaction detection via multi-corpus training. J Biomed Inform. 2015;53:196-207. doi: 10.1016/j.jbi.2014.11.002, PMID 25451103.

7. Davies EA, O'Mahony MS. Adverse drug reactions in special populations - the elderly. $\mathrm{Br} \mathrm{J} \mathrm{Clin}$ Pharmacol. 2015;80(4):796-807. doi: 10.1111/ bcp.12596, PMID 25619317.

8. Hong M, Li S, Tan HY, Wang N, Tsao SW, Feng Y. Current status of herbal medicines in chronic liver disease therapy: the biological effects, molecular targets and future prospects. Int J Mol Sci. 2015;16(12):28705-45. doi: 10.3390/ ijms161226126, PMID 26633388.

9. Liu Y, Ai N, Keys A, Fan X, Chen M. Network pharmacology for traditional Chinese medicine research: methodologies and applications. Chin Herb Med. 2015;7(1):18-26. doi: 10.1016/S16746384(15)60015-6.

10. Geller Al, Shehab N, Weidle NJ, Lovegrove MC, Wolpert BJ, Timbo BB, et al. Emergency department visits for adverse events related to dietary. J Med. 2015;16(373):1531-40 Supplement s N Engl.

11. Nair NP, Chalmers L, Connolly M, Bereznicki BJ, Peterson GM, Curtain C, et al. Prediction of hospitalization due to adverse drug reactions in elderly community-dwelling patients (The PADR-EC score). PLOS ONE. 2016;11(10):1-17.

12. Sen S, Chakraborty R. Revival, modernization and integration of Indian traditional herbal medicine in clinical practice: importance, challenges and future. J Tradit Complement Med. 2017;7(2):234-44. doi: 10.1016/j.jtcme.2016.05.006, PMID 28417092.

13. Charan J, Biswas T. How to calculate sample size for different study designs in medical research? Indian J Psychol Med. 2013;35(2):121-6. doi: 10.4103/0253-7176.116232, PMID 24049221.

14. Pourhoseingholi MA, Vahedi M, Rahimzadeh M. Sample size calculation in medical studies. Gastroenterol Hepatol Bed Bench. 2013;6(1):14-7. PMID 24834239

15. Ezhumalai DG. How Big A Sample Do I Require?. Annals of SBV. 2017;6(1):39-41. doi: 10.5005/ jp-journals-10085-6113.

16. Johnson TP, Wislar JS. Response rates and nonresponse errors in surveys [internet]. JAMA. 2012;307(17):1805-6. doi: 10.1001/ jama.2012.3532, PMID 22550194.

17. von Elm E, Altman DG, Egger M, Pocock SJ, Gøtzsche PC, Vandenbroucke JP. The strengthening the reporting of observational studies in epidemiology (STROBE) statement: guidelines for reporting observational studies. PLOS Med. 2007;4(10):1623-7. doi: 10.1371/journal. pmed.0040296.

18. Von Elm E, Altman DG, Egger M, Pocock SJ, Gøtzsche PC, Vandenbroucke JP. The Strengthening the Reporting of Observational Studies in Epidemiology (STROBE) statement: guidelines for reporting observational studies [internet]. Vol. 370; 2007. Available from: http://www.thelancet. com. Available from: http://www.plosmedicine. org [cited 19/8/2021].

19. Colalto C. What phytotherapy needs: evidencebased guidelines for better clinical practice [internet]. Phytother Res. 2018;32(3):413-25. doi: 10.1002/ptr.5977, PMID 29193357.

20. Andrew R, Izzo AA. Principles of pharmacological research of nutraceuticals. $\mathrm{Br} \mathrm{J}$ Pharmacol. 2017;174(11):1177-94. doi: 10.1111/bph.13779, PMID 28500635.

21. Lüde $S$, Vecchio $S$, Sinno-Tellier $S$, Dopter $A$ Mustonen H, Vucinic $S$, et al. Adverse effects of plant food supplements and plants consumed as food: results from the poisons centres-based PlantLIBRA study. Phytother Res. 2016 Jun 1;30(6):988-96. doi: 10.1002/ptr.5604, PMID 26948409.

22. Posadzki P, Watson L, Ernst E. Herb-drug interactions: an overview of systematic reviews. Br J Clin Pharmacol. 2013;75(3):603-18. doi: 10.1111/j.13652125.2012.04350.x, PMID 22670731.

23. Izzo AA, Hoon-Kim S, Radhakrishnan R, Williamson EM. A critical approach to evaluating clinical efficacy, adverse events and drug interactions of herbal remedies [internet]. Phytother Res. 2016;30(5):691-700. doi: 10.1002/ptr.5591, PMID 26887532. 